\title{
Factors Contributing to Job Engagement in Ugandan Nurses and Midwives
}

\author{
Pauline Bakibinga, ${ }^{1}$ Hege Forbech Vinje, ${ }^{2}$ and Maurice Mittelmark ${ }^{1}$ \\ ${ }^{1}$ Department of Health Promotion and Development, Faculty of Psychology, University of Bergen, \\ Bergen, Christies Gate 13, 5015 Bergen, Norway \\ ${ }^{2}$ Department of Health Promotion, Faculty of Health Sciences, Vestfold University College, Tonsberg, \\ P.O. Box 2243, 3103 Tønsberg, Norway
}

Correspondence should be addressed to Pauline Bakibinga, paulabak80@yahoo.com

Received 20 February 2012; Accepted 29 March 2012

Academic Editors: M. Askarian and B. J. Polivka

Copyright ( $) 2012$ Pauline Bakibinga et al. This is an open access article distributed under the Creative Commons Attribution License, which permits unrestricted use, distribution, and reproduction in any medium, provided the original work is properly cited.

Despite the difficult working conditions many nurses in Sub-Saharan Africa experience resulting in their migration or leaving the profession, there are nurses who thrive and stay engaged. Understanding what factors play a role in enhancing nurses' job engagement might help health care and training institutions develop interventions to enable nurses learn methods to help retain their job engagement. Research in Norway has produced a theory about how job engagement can be protected, called the Self-tuning Model of Self-Care, which was used to explore the phenomenon of job engagement in Ugandan nurses. In-depth interviews were conducted in 2010, with a purposive sample of 15 nurses and midwives. Qualitative content analysis of the data was conducted. Findings from Uganda show that the Self-Tuning Model can be used both as a framework for analysis and as a model of how nurses can promote their experience of job engagement. Nurses should be encouraged to practice habitual introspection and reflection about the satisfactions they derive from work, to enable them retain a high level of job engagement despite the adversities of nursing practice.

\section{Introduction}

Nurses in Sub-Saharan Africa (SSA) play a major role in primary health care delivery, especially in areas where other healthcare cadres are scarce [1]. Nursing practice everywhere is acknowledged as stressful, and nurses in SSA bear especially significant burdens due to very poor pay and heavy workload. This exposes them to stress and burnout [2]. Uganda, like other countries in the SSA region, is experiencing a shortage of health workers arising from insufficient training capacity, and low remuneration combined with poor working conditions, that stimulate too many nurses to change profession or migrate in search for better work and living conditions $[3,4]$.

Even for health professionals who stay in Uganda, the situation is worrying. In a study of its health workforce in 2006 , only $37 \%$ of the health workers were satisfied with their jobs [4]. Previous research on human resources for health in Uganda, including the study just cited, has focused on the causes of shortages and on descriptions of the severity of health worker shortages [5]. Yet, there are health professionals, and nurses in particular, who manage to maintain a high enough level of job engagement that they stay on the job in the Ugandan health care system, despite work adversities. There is an urgent need to understand how some nurses in Uganda manage to cope with their job demands and remain engaged in their work.

A significant addition to nursing the engagement literature comes from Norway, where studies of nurses' job engagement led to the development of the Self-tuning Model of Self-care (hereafter the "Model", Figure 1), which describes self-care processes Norwegian nurses may use to recapture job engagement when it is seriously threatened that burnout may result [6-10].

This suggests the type of research needed to study nurses who thrive, also in Uganda. The desire to examine the utility 


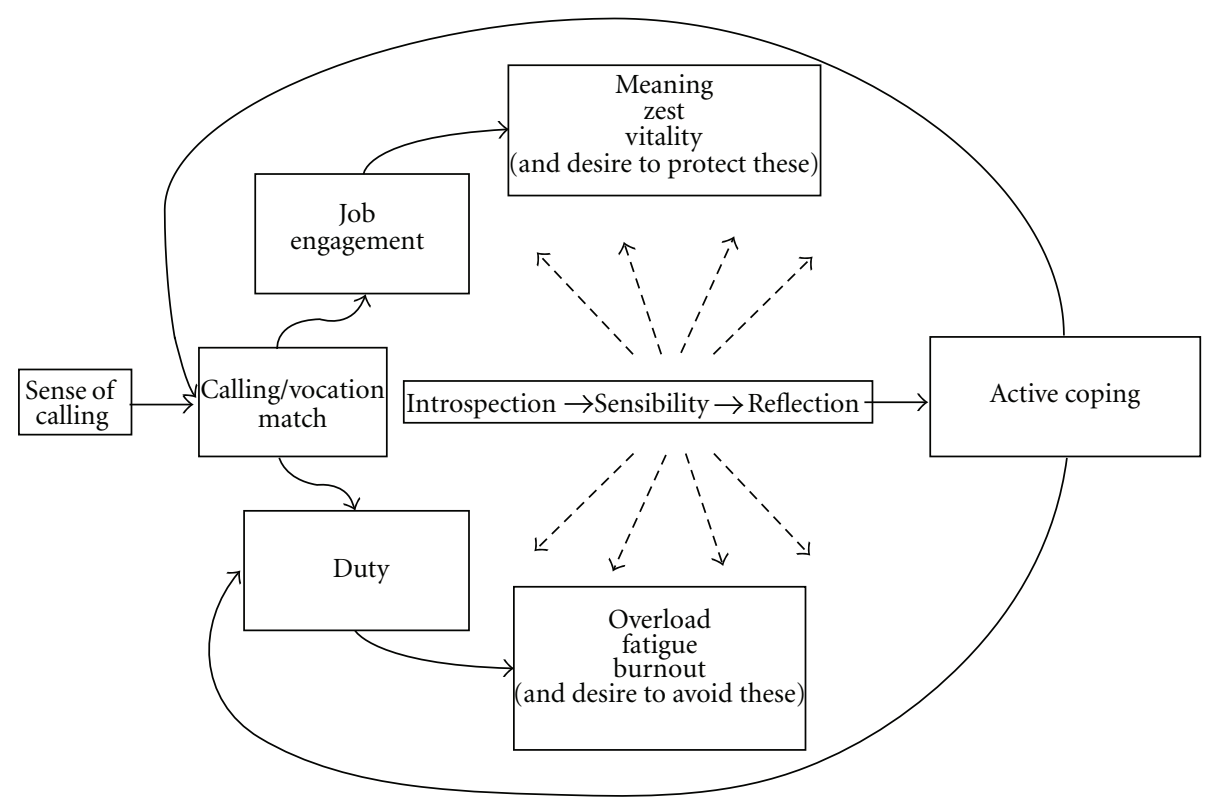

FIGURE 1: The self-tuning model of self-care $[9,10]$.

of the Model in a non-Western setting, and the need for research about nurses' job engagement in Uganda, were complementary stimuli for the study reported here. This study was undertaken with the broader aim of contributing knowledge about ways in which nursing training institutions and health care employers might assist nurses to retain job engagement and to highlight the importance of improving nurses' working conditions.

Schaufeli, and colleagues [11] define job engagement as the "positive, fulfilling, work-related state of mind that is characterised by vigor, dedication, and absorption." Job engagement has also been described as the polar opposite of burnout, with the two existing on a single continuum [12]. Whereas engagement is characterised by energy, involvement, and professional efficacy, burnout is characterised by exhaustion, cynicism, and ineffectiveness. While there is diversity in the conception and measurement of job engagement $[13,14]$, there seems to be consensus that the source of job engagement is the energy, dedication, and involvement that work can provide.

The physical, cognitive, and emotional expression of self that one may experience during work role performance helps fulfil the human spirit [15], giving work meaning beyond simply providing an income. Meaningful work is said to foster motivation and attachment to one's work, whereas absence of meaning leads to disengagement from one's work [16]. Research on predictors of work engagement shows that social support and autonomy, and intrapersonal resources such as optimism, resilience, self-esteem, and selfefficacy, can help mitigate the negative effects of job demands $[17,18]$. Research on nursing job engagement carries vital theoretical and practical implications for nurses' well-being and performance, patients', and organizational outcomes $[14,19,20]$. As empirical research on job engagement has linked high levels of employee engagement to better health and well-being [21], interventions to foster nursing work engagement need to be informed by careful research on its essence and antecedents.

Turning to the self-care Model that is the framework for this study, research in Norway developed empirical evidence which suggests that nurses' job engagement is a process (not a state) originating from a sense of calling to nursing, and the resultant calling/vocation match when one enters the nursing profession, a match that fosters job engagement [9]. A key finding from the study was that all the nurses possessed a sense of calling to the nursing profession. The Model posits that job engagement fosters a nurse's experience of meaningfulness, zest for work and vitality, and the desire to preserve and protect these positive experiences.

The critical finding from the study of the Norwegian nurses was that the nurses engaged in self-care when the negative experiences of nursing seriously threatened their job engagement. The self-care strategy they described had its foundation in life-long habits of deep introspection, leading to sensibility to one's own situation (akin to nurses' knack for sensibility with regard to patients' situations), and reflection about one's situation. This helped the nurses to adopt positive coping strategies, with the aim to retain jobrelated meaning, zest, and vitality, and reduce work overload, fatigue, and risk of burnout.

This entire process of self-care is characterised by the ability to be self-observant and to "tune" one's self and one's work situation in such a way as to retain job engagement. Nearly all the Norwegian nurses studied had at one time or another come close to complete burnout, yet all had managed to regain job engagement by engaging in the selftuning process of self-care.

The aim of this study was to explore the phenomenon of job engagement in nurses with reputations for thriving on 
the job in Uganda, using part of the Model as an analytical framework.

\section{Methods and Participants}

The study employed an exploratory qualitative approach using a combination of phenomenology and hermeneutics [22, 23]. A phenomenological approach was deemed appropriate for an in-depth exploration of the subjective job engagement experiences of Ugandan nurses with reputations for thriving on the job. We are unaware of a similar study conducted in Uganda. Hermeneutical phenomenology was the main method providing for description and interpretations of the nurses' experiences [22]. With an aim of capturing the essence of job engagement in the context of nursing/midwifery practice in Uganda, purposive and snowball sampling of participants [24] enabled us to identify and interview nurses and midwives with reputations for thriving on the job.

The study was conducted in two districts of Uganda, one in the Eastern region (district A) and the other in the Central region (district B). Heads of health units were asked to nominate nurses and/or midwives with reputations for thriving on the job (hereafter the term nurse is used to refer to both nurses and midwives). In district $\mathrm{A}$, four nurses were sampled from different units of a health centre. In district B, three nurses were sampled from different units of a health centre. These nurses were in turn asked to recommend other potential participants.

By snowball sampling, eight more participants were sampled from district B. As a result, nine nurses from public health units and six from private units were sampled. The fifteen female participants were nominated by their colleagues based on criteria which included (1) known to thrive despite working in difficult working conditions, (2) expressed enthusiasm about work, (3) vigorous and highly committed to work, and (4) working for over three years at their present workplace. All participants agreed that they fulfilled the selection criteria. Participants were drawn from various professional nursing and midwifery levels, including enrolled nurse/midwife, registered nurse/midwife, and comprehensive enrolled/registered nurse.

Data were collected via in-depth, individual interviews, which were audio-recorded [25]. Face-to-face interviews were conducted by the first author to give the participants an opportunity to share their experiences while on the job. A thematic interview guide was used and modified during the data collection exercise to ensure that major themes of the study questions were captured. As the study was designed to examine, whether or not, the nature of job engagement as experienced by Ugandan nurses relates to Norwegian nurses, the interview guide was adapted from [7]. In all interviews the opening question was "can you please tell me your work life story?" The interviewer used open-ended questions like, "What is it that made you choose to study nursing? Do you feel that you are in the right place?" One in-depth interview was planned for each participant but with a provision for a repeat, if the need arose [7]. Six interviews were conducted in
English (and not repeated). Four were done in English and repeated in the Luganda language because the respondents found it difficult to express themselves in English. The remaining five interviews were done in Luganda. Thus, nineteen interviews were conducted with the 15 participants. The interviews conducted in Luganda were transcribed into English by the first author, who is fluent in both languages. The interviews took place between March and May 2010 in the interviewees' workplaces or in their homes, and they lasted from approximately one to two hours and fifteen minutes. The interview process was stopped when the point of saturation was judged to have been reached [25], in this case, after nineteen interviews.

Approval for the research project was obtained from the Norwegian Social Science Data Services (NSSD) and the Uganda National Council of Science and Technology (UNCST). Each participant was contacted in person, briefed orally, and in writing about the study, why and how she was recruited, the time needed to participate, and the guarantee of confidentiality of both personal details and study site. Participants signed an informed consent indicating their voluntary participation in the study and their freedom to withdraw at any time.

In order to describe and interpret the nurses' experiences in depth, qualitative content analysis was conducted using a method adapted from Graneheim and Lundman [26] and Whitehead [22]. The interview data was divided into three content areas: calling, zest for work, and vitality, as predefined in the thematic guide. Under each area, the unit of analysis was the specific text about the nurses' experiences while on the job. To explore experiences about calling, participants were asked: what is it that made you choose to study nursing? The analytical tool followed a six-step process. In the first step, the first author read through the transcripts several times to make sense of the data [27]. In the second step, expressions by the nurses that were deemed main, were highlighted and divided into meaning units. The third step involved condensation of the meaning units by providing descriptions close to the text in standard language, thus highlighting the manifest content [26]. In the fourth step, interpretations of the underlying meaning of the meaning units were done. In the fifth step, subthemes were generated from the meaning units. Following a reflective process involving systematic search for other possible themes, discussions amongst the research team, and obtaining feedback from participants, themes were generated. For example under calling, four participants: 4 , 6,7 , and 15 reported that they chose the nursing profession after certain circumstances in their lives that left them with no other option but nursing. We categorised this under "following events in life." The analysis was done in two stages, first within cases and then across cases. Later, we compared the results to those of the Norwegian nurses [6].

To enhance credibility of the study's findings, we adopted the strategies recommended by Creswell and Miller [28]. An interview guide was used during the interviews to ensure that all participants responded to similar questions, thus allowing for a degree of consistency throughout the interviews. The interview guide was pilot-tested with six nurses, who were 
not part of the sample analysed for this study. This group of nurses was aware of the nature of the study and ethical approval for a pilot was granted by NSSD and UNCST. Clarifications were sought from the participants during the interview process, by the interviewer paraphrasing points that might require clarification. All participants were asked to read the transcript of their interview, all agreed, and all expressed the opinion that the transcripts were correct. During the analytical process, discussions amongst the coauthors were undertaken to ensure a common understanding of the data and interpretation of emergent themes [29].

\section{Findings}

Among the 15 nurses and midwives who participated in the study, five were double trained-registered nurses/midwives, four were enrolled midwives, three were registered midwives, and one was a registered nurse while two were comprehensive nurses. Nine participants were from public (governmentaided) health units, three from private-not-for-profit (faithbased) units, and the remaining three from private-for-profit health units. All the participants worked in various hospital departments including medicine, gynaecology, maternity, antenatal clinic, outpatients/emergency, neonatal intensive care, and surgical departments of different health units in the two districts. The participants' ages ranged from 28 to 49 years with a mean age of 33.5 years. The years of working experience ranged from 3 to 29 with a mean of 11.1 years.

The emergent themes under each job engagement factor are presented in Table 1. Following the analysis, we discovered cohesion in themes generated from the Ugandan nurses and their Norwegian counterparts. Based on this, the findings of this study are presented in a table adapted from Vinje and Mittelmark [6]. To elaborate on the findings, anonymous quotations bearing the participant's number according to the order of the interviews are presented.

Overall, the nurses expressed high levels of commitment and dedication to their work, despite the adversities they faced. The nurses' accounts reveal passionate individuals driven by a search for meaning and meaningfulness in life. The search for meaningfulness was reported as a desire to be of service to others, thus making a difference in their own lives and the lives of others.

The data revealed high moral and ethical standards related to personal, nursing, and religious values. As one nurses recounted:

Service above self is my motto. (...) God has blessed me with many talents, which I am using to make other people's lives better. Nursing is a service, equivalent to a mission from God. We are called to go out and reduce suffering (N-11).

The nurses' expressions were those of individuals who clearly derived meaning from their work:

Right from childhood, I was raised to believe that there was no point in doing something that has no meaning for me or for others.
(...) Therefore, I have to enjoy myself as I work or else it is meaningless. No amount of money can equal to that. I offer a valuable service to society so I am contented (N-5).

The nurses' accounts revealed dedicated and hardworking individuals that in their daily work contend with challenges including dealing with demanding clients and bosses. Despite these challenges, they are able to thrive. All together, the nurses exhibited skills that enable them to cope on the job and derive satisfaction from the work they do. These vital skills, introspection, and reflection, seem to have been nurtured throughout one's life course-right from childhood-and later strengthened in school and maintained at the work places. One nurse from a private health unit said this in response to a question about where she had learned to deal with her work-life situation:

Mostly my family background and upbringing helped model me. I cannot attribute this to school or my workplace alone. I believe the reason I have been able to persist in this is that I was trained well by my parents. I also rely on God (N-8).

By reflection on their work and other life's circumstances they are able to balance between personal aspirations and reality. A nurse who had struggled with midwifery before changing to general nursing said this on her move:

Obstetric emergencies always scared me. I was never relaxed while on duty because I kept on anticipating the worst. With time, after careful reflection about who I am and what I wanted to be, I made a decision to move to general nursing. (...) I enjoy myself and certainly do a better job. I am so glad I made the move (N-5).

The themes were consistent irrespective of place of work, years of work experience and age. This is so even though work conditions differ in both private and public settings.

\section{Sense of Calling and the Search for Meaning}

Calling is defined by "feelings of having a mission or purpose, including commitment to and healthy absorption in one's vocation, and having the feeling of being in the right place" [7]. From the Ugandan nurses' experiences, search for meaning is revealed from their tales as follows.

(i) Listening to the Call. In response to what made them join nursing practice, we discovered that for the majority of the nurses (11 out of 15), a search for meaning that nursing provides in life could be traced to childhood dreams about working as a nurse or within health care service:

From when I was little, I admired nurses (...) My mother, having realised my interest, encouraged me daily. She helped me prepare for this career. She $(. .$.$) told me that nurses help$ 
TABLE 1: Summary of results on the foundation and nature of job engagement among Ugandan nurses and midwives.

\begin{tabular}{|c|c|c|c|}
\hline $\begin{array}{l}\text { Foundation for revealing the } \\
\text { essence of job engagement }\end{array}$ & \multicolumn{3}{|c|}{ Introspection and reflection } \\
\hline Essence of job engagement & \multicolumn{3}{|c|}{ Nursing gives life meaning } \\
\hline Aspects of job engagement & Calling & Zest for work & Vitality \\
\hline Contribution to meaningfulness & $\begin{array}{l}\text { Path to one's search for } \\
\text { meaningfulness }\end{array}$ & Experiencing meaningfulness & Holding onto the meaning \\
\hline $\begin{array}{l}\text { Characteristics of experiencing } \\
\text { job engagement }\end{array}$ & $\begin{array}{l}\text { (i) Listening to the call } \\
\text { (ii) Experiences of being driven } \\
\text { (iii) Experiences of being in the } \\
\text { right place } \\
\text { (iv) Experience of being empowered } \\
\text { with required skills } \\
\text { (v) Following events in life }\end{array}$ & $\begin{array}{l}\text { (i) Feelings of being appreciated, } \\
\text { of being of service } \\
\text { (ii) Job demands (such as } \\
\text { workload) and resources (such as } \\
\text { equipment) } \\
\text { (iii) Interpersonal relationships } \\
\text { (iv) Feelings of being in the right } \\
\text { place }\end{array}$ & $\begin{array}{l}\text { (i) Inner power possessed or } \\
\text { replenished after rest (including } \\
\text { prayer and meditation) } \\
\text { (ii) Interpersonal relationships } \\
\text { (iii) Job demands and resources }\end{array}$ \\
\hline
\end{tabular}

needy people and had to act fast and efficiently. I learned to appreciate nursing from her $(\mathrm{N}-2)$.

(ii) Experiences of Being Driven, Wanting to Be of Service. A need to be of service seems to serve as a driving force in their daily work, illustrated by this statement:

Out of experience I know what it means to be in need. Therefore helping people in need is what drives me. (...) When you have been in a situation, somewhere between life and death, you appreciate the importance of someone helping you out (N-11).

(iii) Experience of Being in the Right Place. In response to a question about whether they were in the right place or not, all said they were in the right profession, and all but two agreed that they were in the right job:

I am in the right place because at the end of each day I assess my activities. Most of the time, I am happy about my work. (...). The pay is not so good but as a work place, it is comfortable for me to work here. I am able to do what is expected of me (N-6).

The remaining two agreed that they were in the right profession despite having unsatisfactory jobs.

(iv) Experience of Being Empowered with Required Skills. All the nurses interviewed expressed interest in professional skills development. Of the fifteen, only three had not upgraded themselves professionally, and these three were planning to resume school in the near future.

(v) Following Events in Life. Contrary to the pattern in the findings reported above, some respondents reported that they ended up in nursing because they had nothing else to do:

My father passed on before I completed my Ordinary level exams. After my exams, I could not proceed to Advanced level because I had no school fees. (...) Although it [nursing] was not my choice, I with time learned to accept and appreciate it because I was determined to do my very best to get the best out of it. Right now, I cannot imagine myself elsewhere (N-7).

\section{Zest for Work: Experiencing the Meaning}

Zest for work is defined by "feelings of vocation-related joy, happiness, enthusiasm, and dedication" [7]. These Ugandan nurses reveal an active search for and experience of meaning in their work. These nurses attach meaning to their work through seeking to enjoy themselves while making a difference in other people's and their own lives.

My work is a big part of my life so it has to be meaningful in terms of rewards-emotionally and financially as a means of survival. (...) I feel good when I offer a service. The financial benefits are so poor but I survive. What I get is emotional. Without meaning in life there is no point in doing anything (N-3).

(i) Feelings of Being Appreciated. Zest for work is experienced when they feel that they are appreciated by bosses and clients for the services they offer.

(...) but I know my clients who have told me so routinely ( $\mathrm{sic}$ ) that they value my work. They call me to express their gratitude and some I even meet in town and they acknowledge me. I love my job and my immediate supervisor is very understanding and considerate. (...) That is something I value about my present work (N9).

(ii) Job Demands and Resources Equipment, Supplies, and Work Hours (Workload). Zest for work is experienced when work resources that they need to work with are available. This is in addition to manageable work hours. 
A good working life involves a short work shift, understanding and considerate bosses, courteous and grateful patients and their relatives. This is in addition to a good work team. When I have the above, it is easy for me to enjoy my work.

Many times, I cannot have this. Our work shifts can be long because of shortages of staffs but I usually get clients who show gratitude and often that is more than enough for me to enjoy my work (N-4).

(iii) Interpersonal Relationships: Relationships with Workmates, Supervisors/Superiors, and Patients. Zest for work is experienced when they share duties with workmates with similar values and interest in work.

(...) It is that day when I come to work and find the labour ward or waiting room full of patients I am going to attend to and when my working team is so vigorous. You know, sometimes you get colleagues who are willing to work so you know that when you are with so and so on duty, work has to flow because each one understands the other (N-9).

This is also related to relationships with superiors and peers and patients who respect them as human beings and professionals and value them for their contribution. "Appreciation especially monetary from bosses and tips, kind words and a good team with team spirit constitute a good working life for me (N-12).”

What I can consider as good work life is like when my boss says thank you. I appreciate it because then you realise that you have done something that has been observed. Even patients who appreciate me contribute to a good work life for me. This is most especially when you work on a condition that is strange and tough and you end up succeeding. That gives me joy. It makes me happy to know that I have done something right (N-1).

(iv) Feelings of Being in the Right Place. Meaning is experienced as a feeling of contentment that comes from being in the right place.

"I am in the right place because despite the poor pay, I still get out of my home to come and serve. I love midwifery and I am reluctant to change to anything else. This place is right for me..." (N-15).

In addition, zest for work is further fuelled by a feeling or realisation that other areas of one's life are okay. They acknowledge that their personal lives cannot be separated from their careers.

\section{Vitality: Holding onto Meaning}

Vitality is defined by "feelings of vigour, strong life energy, and the will to exert oneself" [7]. Vitality is about energy. In the present study, meaning was maintained by the energy the nurses felt while at work. Vitality is revealed as inner power possessed or reclaimed after a rest-leave, or sleep, or simply taking time off to relax:

For instance after a good night's rest or from leave or when I find an equally energetic team to work with. This is because in the first two situations I feel fresh and energetic so I can do any work that is available. The fact is that with this kind of work, one is not independent that is why other people's energy affects you sometimes (N-13).

In holding onto meaning, interpersonal relationships including relationships with coworkers, superiors, and patients are important. This is in addition to availability of equipment or supplies and the workload-job demands and resources. When job resources are available or positive, the energy is high and when they are inadequate, the energy is low or depleted.

(...) My work here is like a sacrifice. Therefore, I would not want to deal with rude clients. Someone can easily spoil your day by a simple but inconsiderate word and when it is done, I have to struggle to reclaim my energy. Rude and arrogant patients kill my energy for work.

\section{Discussion}

The findings of this study support earlier findings from Norway $[7,9]$ regarding the essence of job engagement in the face of adversity. Whereas the duties and tasks of nursing are fundamentally the same everywhere, contextual factors influence the ways in which different individuals and groups experience the same phenomenon, in this case nursing practice. Although Norway is a high-income country and Uganda is ranked among the low-income countries, there were obvious similarities in the experience of job engagement as revealed in the stories of the nurses from the two countries.

As did Vinje and Mittelmark [9], we found that within this group of thriving Ugandan nurses, calling to the nursing profession triggers a process that is mediated by introspection and reflection about their work life, enabling the nurses to adjust and cope better on the job. Eleven of the fifteen nurses reported that the call to work within the health care field was felt right from childhood. Others felt a calling in relation to a major life-changing event or in relation to God; in all cases, these nurses were assured of what they had to do. They possessed a strong conviction that they had been called to work in health care. It has been suggested that a call may be experienced outright and clear, as from God, or as a consequence of major events in life $[30,31]$. Four of the nurses' sense of calling developed only after events in life "delivered" them to nursing. These were nurses for whom entering nursing was a practical move. This is a common scenario in Uganda, where educational policies are such that people often end up taking courses that were 
not primarily desired. The Joint Admissions Board (JAB) of the Ugandan Ministry of Education and Sports coordinates all admissions to public tertiary institutions in the country by ascertaining available space and setting requirements for admission. For instance, in their 2010/2011 guidelines it was stipulated that the diploma course in registered midwifery is only open to female applicants [32]. In addition, it is common to find a student settling for what is available since the admission process is determined by grades rather than by aptitude, especially for those who cannot afford to pay their way through college.

From the Ugandan nurses' experiences, calling to the profession is important for job engagement, as it were in Norwegian nurses' experiences [7]. Those who joined the profession due to lack of better options also professed high levels of energy and dedication to work. This may be due in part to the importance of value congruence in people's lives $[9,19,33]$. Nursing is a highly value drive profession, a context in which four study participants became aware of and found a balance between their personal values, those of nursing and those of the workplace. They were thus enabled to derive satisfaction from their work and thus experience job engagement. We speculate that in a setting where people take on professions for practical reasons, or even out of desperation, it is still possible for one to be engaged in one's work. This highlights the possible importance of training institutions and workplaces' role in enabling professionals prepare for work and maintain high engagement levels, especially under difficult circumstances.

This study highlights the importance of calling and meaning to the maintenance of job engagement as observed by Vinje and Mittelmark [9], and the results are also consonant with other studies that have illuminated engagement as characterised by vigour and dedication [13]. Driven by the search for meaning, in the face of work adversity, thriving nurses use personal and job resources to remain engaged at work. The experience of nursing engagement rests heavily on use of available resources, intra- and interpersonal, enabling the nurses to cope with job demands. This is consistent with findings by Hakanen and colleagues [17], who in a study of Finnish dentists observed that in the face of adversity, dentists manage to cope with their job demands and stay engaged with the help of job resources.

Previous research points to the importance of social support, including that of superiors and peers, in fostering nurses' job satisfaction and engagement at work [19, 34]. In accord with the earlier findings, the nurses in this study consistently related the importance of interpersonal relationships in the maintenance of meaning and workrelated meaningfulness. Relationships with peers, superiors, and clients were highlighted as important factors in their experience of job engagement. The relationships were either positive, fostering job engagement or negative, serving as barriers to job engagement.

Work conditions in public and private health sectors in Uganda vary [4] and the nurses' accounts in this study revealed differences in sources of stress depending on the workplace, whether public or private. Nabirye [2], in her work on occupational stress, job satisfaction, and job performance among hospital nurses in Uganda, observed that nurses in the public sector had higher levels of occupational stress and lower levels of job satisfaction and performance. However, the essence of job engagement within the two groups in this study was the same. Another interesting finding is the influence of religion on the personal and work values and coping mechanisms of this group of nurses. All of the nurses mentioned God as a source of sustenance in the face of adversity.

We speculate that nurses' ability to thrive despite adversity may be dependent upon having a positive outlook on life, more so than avoidance of stressors. By being aware of and utilising the resources (personal and job) at their disposal, they are able to deal with stress effectively, mitigating its deleterious effects and fostering thriving on the job. Through introspection and reflection (personal resources), they seem able to review their circumstances and ultimately come up with the best actions to foster thriving on the job. Personal resources have been linked to resiliency and while resilience has been suggested as a facilitator of work engagement, studies have shown that employees who score highly on resilience, self-efficacy, and optimism are more highly engaged [13]. Therefore, in promoting engagement at work and satisfaction and ultimately retention, nurses ought to be empowered to engage in self-care. A health promotion perspective on work includes providing a supportive environment, to enable workers to gain control over their own health. In accordance with the basic principles of creating health-promoting workplaces, health care managers need to make the work environment conducive such that all nurses have the job resources they require. The role of resources in coping will be described in detail in a later analysis.

\section{Study Limitations}

This study includes only female nurses with reputations for thriving, and that have stayed on the job despite the adversities they face in their vocations. Further, nurses in the study were recruited from urban and suburban areas, and possible differences in the experience of job engagement by rural nurses cannot be ascertained with the data available. Another important point is that most of the interviews were conducted in Luganda and translated into English. There is no doubt that important elements of nuance in the raw data cannot survive the translation process.

\section{Implications and Conclusions}

This study contributes to the literature, by providing evidence for nursing job engagement as process characterised by meaning and expressed as dedication and vigour on the job, as previously postulated in the self-care model. We observed that many aspects of job engagement in this subSaharan African context are similar to the experience of job engagement in other contexts, particularly in Norway where a highly comparable study has previously been undertaken. Future research is necessary to explore job engagement within nursing practice on a larger scale and within other 
health care professions to inform human resource management policy and practice.

Nurses who are highly engaged in their work are vital to the functioning of the health system in Uganda as elsewhere. It seems job engagement can be nurtured, and the nurses in this study were skilled at engaging intra- and interpersonal resources to protect their job engagement. The findings suggest that during their training and also on the job, nurses should learn the skills for, and practice habitual introspection and reflection about the satisfactions they derive from their work, to help them retain a high level of job engagement. As Uganda and other countries in the Global South work to build health workforces, there is a need to incorporate strategies in training schools and healthcare workplaces which provide health promoting environments and enable nurses to acquire the perspectives and skills that nurture job engagement.

\section{Acknowledgments}

This doctoral study of P. Bakibinga was funded by a grant from the Norwegian State Educational Loan Fund (Lånekassen). The authors express their gratitude to the nurses who participated in this study and to Enid Ashaba Mugarura for her invaluable help during the trial phase of the study.

\section{References}

[1] O. K. Munjanja, S. Kibuka, and D. Dovlo, The Nursing Workforce in Sub-Saharan Africa, International Council of Nurses, Geneva, Switzerland, 205.

[2] R. C. Nabirye, Occupational stress, job satisfaction and job performance among hospital nurses in Kampala Uganda, Dissertation, University of Alabama, Birmingham, UK, 2010.

[3] Moh. Uganda, Annual Health Sector Performance Report 2006/7, Ministry of Health, Kampala, Uganda, 2007.

[4] A. Hagopian, A. Zuyderduin, N. Kyobutungi, and F. Yumkella, "Job satisfaction and morale in the ugandan health workforce," Health Affairs, vol. 28, no. 5, pp. w863-w875, 2009.

[5] C. W. Matsiko and J. Kiwanuka, "A review of human resource for health in Uganda," Health Policy and Development, vol. 1, no. 1, pp. 15-20, 2003.

[6] H. F. Vinje and M. B. Mittelmark, "Deflecting the path to burnout among community health nurses: how the effective practice of self-care renews job engagement in the face of adversity," International Journal of Mental Health Promotion, vol. 8, pp. 36-47, 2006.

[7] H. F. Vinje, Thriving despite adversity: job engagement and self-care among community nurses, Dissertation, University of Bergen, Bergen, Norway, 2007.

[8] H. F. Vinje and M. B. Mittelmark, "Job engagement's paradoxical role in nurse burnout," Nursing and Health Sciences, vol. 9, no. 2, pp. 107-111, 2007.

[9] H. F. Vinje and M. B. Mittelmark, "Community nurses who thrive: the critical role of job engagement in the face of adversity," Journal for Nurses in Staff Development, vol. 24, no. 5, pp. 195-202, 2008.

[10] H. F. Vinje, "Spenningsfylt omsorgspraksis og selvomsorg: hvordan kan jobbengasjement bevares og stimuleres i sykepleien?" Tidskrift for Kreftsykepleie, vol. 24 , no. 4, pp. 6$13,2008$.

[11] W. B. Schaufeli, M. Salanova, V. Gonzalez-Roma, and A. B. Bakker, "The measurement of engagement and burnout: a two sample confirmatory factor analytic approach," Journal of Happiness Studies, vol. 3, pp. 71-92, 2002.

[12] C. Maslach and M. P. Leiter, The Truth about Burnout, JosseyBass, San Francisco, Calif, USA, 1997.

[13] A. B. Bakker, W. B. Schaufeli, M. P. Leiter, and T. W. Taris, "Work engagement: an emerging concept in occupational health psychology," Work and Stress, vol. 22, no. 3, pp. 187200, 2008.

[14] M. R. Simpson, "Engagement at work: a review of the literature," International Journal of Nursing Studies, vol. 46, no. 7, pp. 1012-1024, 2009.

[15] W. A. Kahn, "Psychological conditions of personal engagement and disengagement at work," The Academy of Management Journal, vol. 33, no. 4, pp. 692-724, 1990.

[16] D. R. May, R. L. Gilson, and L. M. Harter, "The psychological conditions of meaningfulness, safety and availability and the engagement of the human spirit at work," Journal of Occupational and Organizational Psychology, vol. 77, no. 1, pp. 11-37, 2004.

[17] J. J. Hakanen, A. B. Bakker, and E. Demerouti, "How dentists cope with their job demands and stay engaged: the moderating role of job resources," European Journal of Oral Sciences, vol. 113, no. 6, pp. 479-487, 2005.

[18] A. B. Bakker, J. J. Hakanen, E. Demerouti, and D. Xanthopoulou, "Job resources boost work engagement, particularly when job demands are high," Journal of Educational Psychology, vol. 99, no. 2, pp. 274-284, 2007.

[19] Y. M. Freeney and J. Tiernan, "Exploration of the facilitators of and barriers to work engagement in nursing," International Journal of Nursing Studies, vol. 46, no. 12, pp. 1557-1565, 2009.

[20] M. R. Simpson, "Predictors of work engagement among medical-surgical registered nurses," Western Journal of Nursing Research, vol. 31, no. 1, pp. 44-65, 2009.

[21] W. B. S. Schaufeli, "Work engagement: an emerging psychological concept and its implications for organizations," in Research in Social Issues in Management, S. W. Gilliland, D. D. Steiner, and D. P. Skarlicki, Eds., pp. 135-177, Information Age, Greenwich, Conn, USA, 2007.

[22] L. Whitehead, "Enhancing the quality of hermeneutic research: decision trail," Journal of Advanced Nursing, vol. 45, no. 5, pp. 512-518, 2004.

[23] J. A. Smith, P. Flowers, and M. Larkin, Interpretative Phenomenological Analysis: Theory, Method and Research, Sage, Thousand Oaks, Calif, USA, 2009.

[24] J. W. Creswell, Research Design: Qualitative, Quantitative, and Mixed Methods Approaches, Sage, Thousand Oaks, Calif, USA, 2nd edition, 2003.

[25] S. Kvale, Interviews: An introduction to Qualitative Research Interviewing, Sage, Thousand Oaks, Calif, USA, 1996.

[26] U. H. Graneheim and B. Lundman, "Qualitative content analysis in nursing research: concepts, procedures and measures to achieve trustworthiness," Nurse Education Today, vol. 24, no. 2, pp. 105-112, 2004.

[27] J. W. Creswell, Research Design: Qualitative, Quantitative, and Mixed Methods Approaches, Sage, Thousand Oaks, Calif, USA, 3rd edition, 2009.

[28] J. W. Creswell and D. L. Miller, "Determining validity in qualitative inquiry," Theory into Practice, vol. 39, no. 3, pp. 1$130,2000$. 
[29] G. C. Christians, "Ethics and politics in qualitative research," in The Sage Handbook of Qualitative Research, N. Denzin and Y. S. Lincoln, Eds., pp. 139-164, Sage, Thousand Oaks, Calif, USA, 3rd edition, 2005.

[30] E. Jeffries, "Hearing the call to nursing.", Nursing, vol. 28, no. 7, pp. 34-35, 1998.

[31] B. J. Dik and R. D. Duffy, "Calling and vocation at zork: definitions and prospects for research and practice," Counseling Psychologist, vol. 37, no. 3, pp. 424-450, 2009.

[32] J. A. B. Uganda, Guidelines to Applicants for Entry into Tertiary Institutions for Diploma Courses 2010/2011 Admissions, Ministry of Education and Sports Uganda, Kampala, Uganda, 2010.

[33] B. Verplanken, "Value congruence and job satisfaction among nurses: a human relations perspective," International Journal of Nursing Studies, vol. 41, no. 6, pp. 599-605, 2004.

[34] A. Zuyderduin, J. D. Obuni, and P. A. McQuide, "Strengthening the Uganda nurses' and midwives' association for a motivated workforce," International Nursing Review, vol. 57, no. 4, pp. 419-425, 2010. 


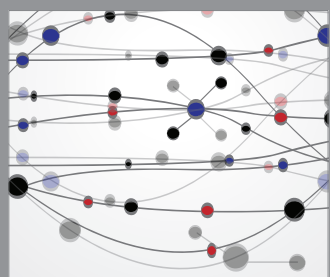

The Scientific World Journal
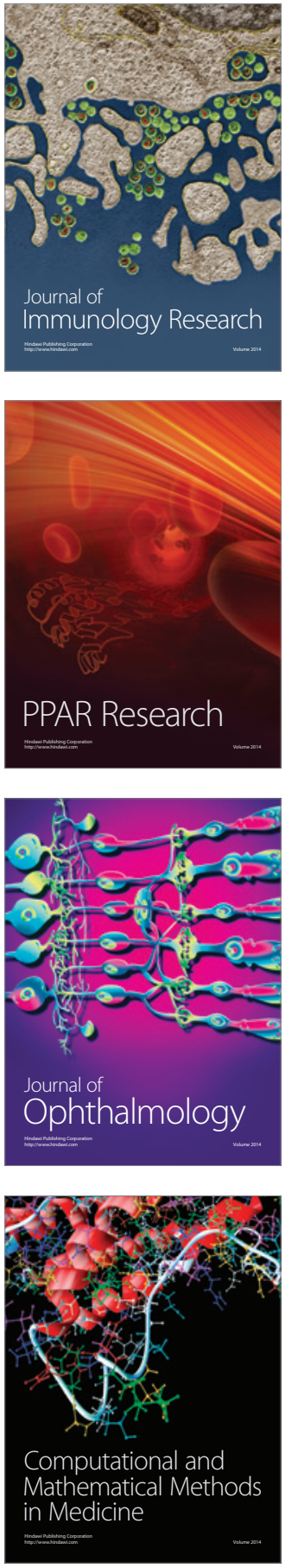

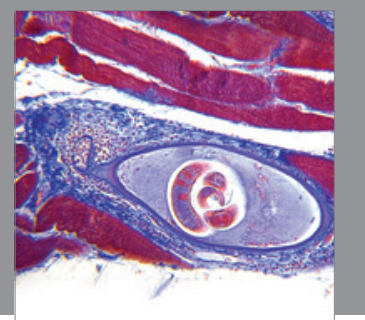

Gastroenterology

Research and Practice
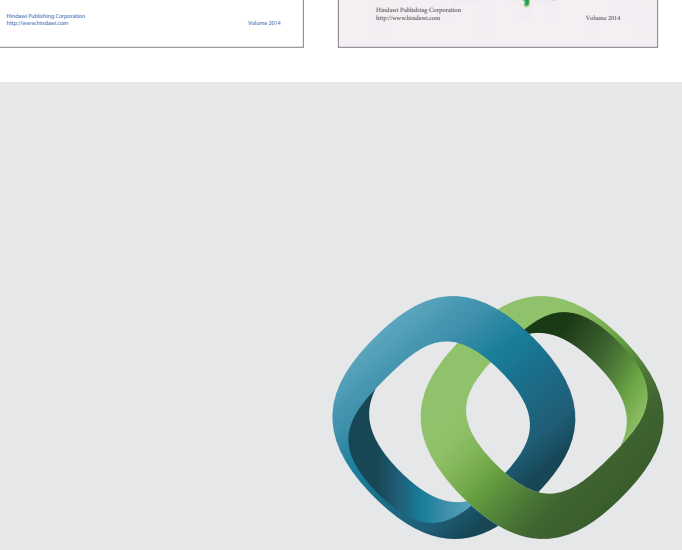

\section{Hindawi}

Submit your manuscripts at

http://www.hindawi.com
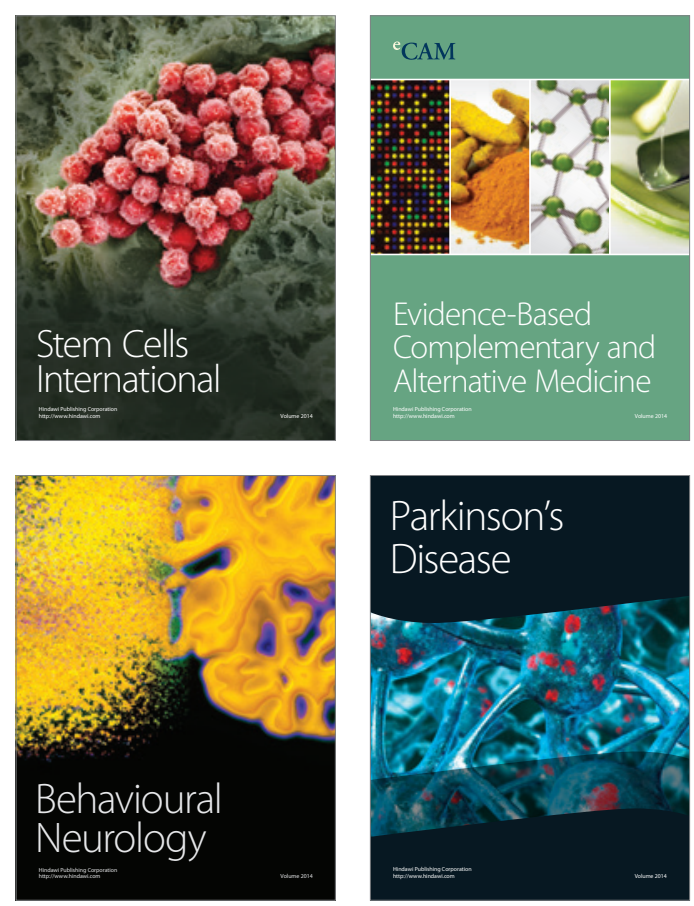

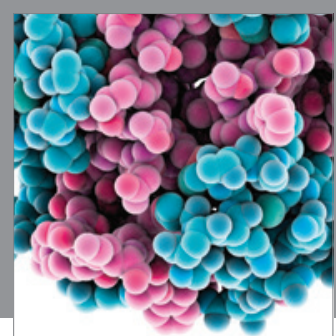

Journal of
Diabetes Research

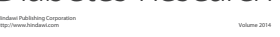

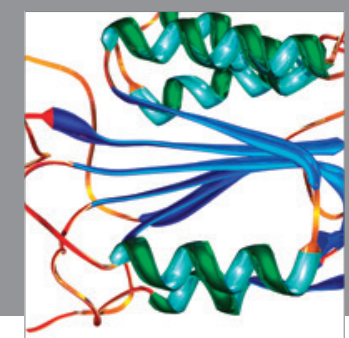

Disease Markers
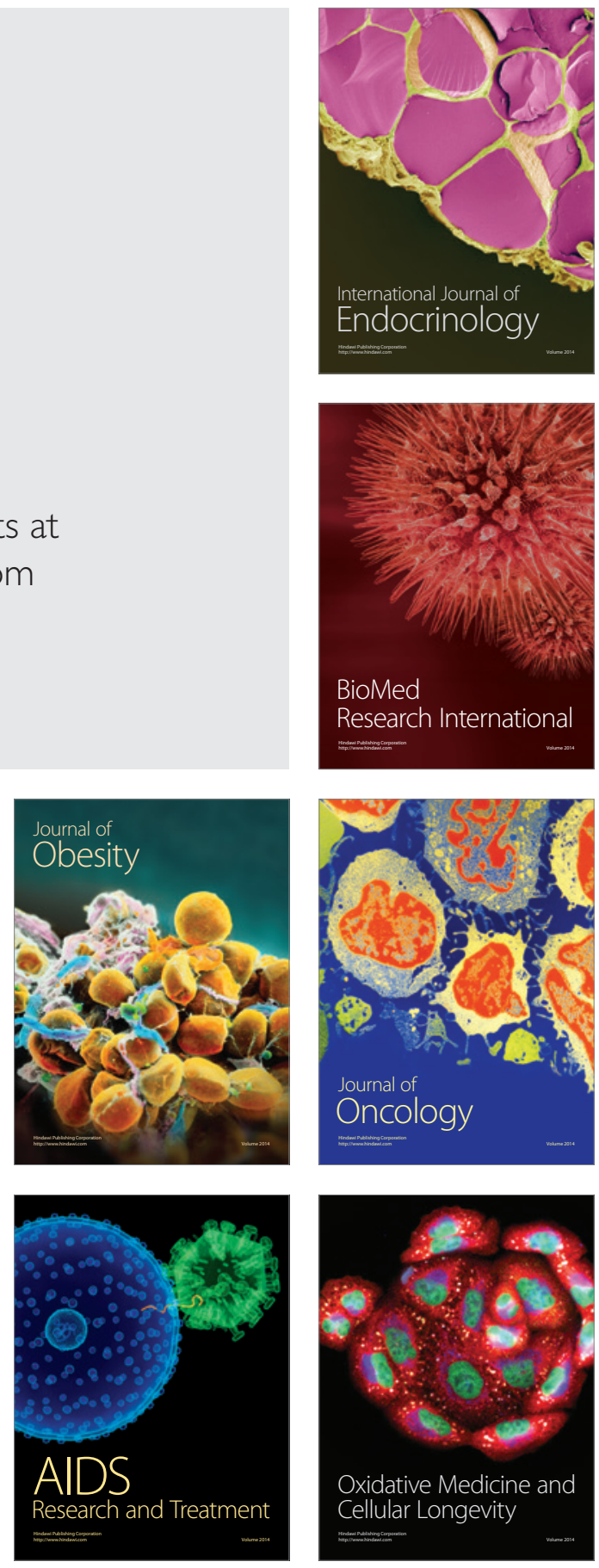